Article

\title{
Decoupling and Decomposition Analysis of Residential Energy Consumption from Economic Growth during 2000-2017: A Comparative Study of Urban and Rural Guangdong, China
}

\author{
Yong Yang ${ }^{1,2,3}$, Junsong Jia ${ }^{1,2, * \mathbb{D}}$, Adam T. Devlin ${ }^{1,2,4}$, Yangming Zhou ${ }^{1,2}$, Dongming Xie 5 \\ and $\mathrm{Min} \mathrm{Ju}^{1,2}$ \\ 1 School of Geography and Environment, Jiangxi Normal University, Nanchang 330022, China; \\ 18607045927@163.com (Y.Y.); atdevlin@jxnu.edu.cn (A.T.D.); ymzhou2005@163.com (Y.Z.); \\ jxsddljm@126.com (M.J.) \\ 2 Key Laboratory of Poyang Lake Wetland and Watershed Research, Ministry of Education, \\ Jiangxi Normal University, Nanchang 330022, China \\ 3 Graduate School, Jiangxi Normal University, Nanchang 330022, China \\ 4 Institute of Space and Earth Information Science, The Chinese University of Hong Kong, Shatin, \\ Hong Kong 999077, China \\ 5 Tourism College, Jiangxi Science \& Technology Normal University, Nanchang 330013, China; \\ jxstnu_xdm@jxstnu.edu.cn \\ * $\quad$ Correspondence: jiaaniu@126.com; Tel.: +86-791-8812-0440
}

Received: 21 July 2020; Accepted: 25 August 2020; Published: 28 August 2020

\begin{abstract}
Residential energy consumption (REC) is now the second largest energy sector in China. However, decoupling analysis of REC has not received enough attention. Here, we explore the decoupling relationship between REC and economic growth in urban and rural Guangdong from 2000 to 2017. First, we use the Tapio decoupling model to study the decoupling state. Then, key drivers affecting the decoupling were explored by combining the Tapio decoupling model with the Log-mean Divisa Index (LMDI) method. Finally, the decoupling efforts were evaluated by using the decoupling efforts model. The main results are as follows: (1) The decoupling state in urban regions was better than that in rural regions. Urban regions experienced weak decoupling (WD) in most years during 2000-2017, while expansive negative decoupling (END) mostly was seen in rural regions. (2) The per capita income effect was the most important driver inhibiting decoupling in Guangdong urban and rural regions. The energy intensity effect was the biggest driver promoting decoupling in urban Guangdong, followed by the family size effect. In contrast, the family size effect exerted the dominant influence on accelerating the decoupling in rural Guangdong. Overall, the household effect inhibited decoupling in urban regions, but promoted decoupling in rural regions. (3) The decoupling efforts results suggest that the energy efficiency improvement played a major role in the decoupling efforts of urban Guangdong, while the decrease of family size in rural Guangdong was the leading contributor to the decoupling efforts.
\end{abstract}

Keywords: residential energy consumption; Tapio decoupling model; LMDI; decoupling effort; urban and rural Guangdong

\section{Introduction}

China has become the largest energy consumer in the world, leading to the environment coming under strain [1]. As the largest developing country, China is still in the middle stages of industrialization and urbanization [2]. Its economic development is difficult to realize without energy 
consumption [3]. Therefore, it is critical to coordinate its economic growth and energy consumption. Currently, residential energy consumption (REC) is the second largest energy consuming sector in China, accounting for around $12 \%$ of the total energy consumption in 2015 [4,5]. However, the average share of REC to the total energy consumption is about $31 \%$ in the world [6]. With further development of urbanization and industrialization expected, China's REC is likely to increase in the future [7-9]. Therefore, it is crucial to accelerate the decoupling process between REC and economic growth.

Previous studies that investigated the REC of China have grown numerous over the past few decades [10,11], and they mainly focus on calculating the REC and exploring the factors affecting REC from the perspectives of nation, region and urban-rural contrast [12]. The source of the REC is often studied by many researchers, finding that REC includes direct and indirect REC. The former refers to energy consumption in a residents' daily life, such as cooking, lighting, heating and private transport, etc. [13]. The latter describes energy consumption caused by the embodied energy consumed during the various stages of the non-energy goods and services, such as production, transportation and marketing [14]. In general, there are two mainstream methods to calculate the indirect REC, namely, the consumer life approach (CLA) and input-output analysis (IOA) $[15,16]$. Using these methods, many researchers quantified the direct REC $[7,17,18]$ and the indirect REC in China [12,19-21].

When it comes to the factors affecting China's REC, the main drivers, such as the energy structure, energy intensity, population, income, urbanization and so on, are usually discussed [7,22]. There are two widely used decomposition methods to explore the issue, namely, structural decomposition analysis (SDA) and index decomposition analysis (IDA) [23]. The SDA is based on IO tables, which yields more accurate decomposition results. However, the IO tables are only available in specific years, thus limiting the application of SDA [1,24]. Conversely, IDA can analyze changes between any years based on aggregate data, as well as providing some optional indices [25]. Among all of these indices, Log-mean Divisa Index (LMDI) is the preferred decomposition method that is widely utilized because it has no unexplainable residuals and its being able to handle zero values problems [26-28]. Zhao, et al. [29] employed the LMDI to decompose the REC in urban China between 1998 and 2007 from the perspectives of disaggregated product and activity. The LMDI was utilized by Nie and Kemp [6] to research the drivers of the REC in China between 2002 and 2010. Zhang and Bai [17] also used LMDI to investigate the factors governing the REC in Shandong urban and rural regions from 1995 to 2013.

While many studies have extensively studied the REC of China with robust results, little attention concentrates on exploring the decoupling relationship between the REC and economic growth. For example, Zhang and Bai [17] explored the decoupling state of REC in Shandong, which mainly focused on quantifying the decoupling status. To understand this issue in-depth, several questions need to be answered. These include the following: What is the decoupling status between REC and economic growth? What are the underlying factors affecting the decoupling? How can the specific decoupling efforts made by each factor be understood?

Under such a circumstance, our study selects Guangdong Province as a presentative case. Figure 1 shows its location. As the most developed province in China, Guangdong accounts for $10.85 \%$ of national gross domestic product (GDP) and $8.03 \%$ of population in 2017, leading to about $7.25 \%$ of China's total final energy consumption [30]. To our knowledge, Guangdong was chosen by the National Development Reform Commission (NDRC) as one of the first batch of low-carbon provinces on 18 August 2010 [31]. Thus, it is important for Guangdong as well as the national level to coordinate the economic growth and energy consumption. Meanwhile, Guangdong residents' per capita income and life quality are higher than those of the national average, which may lead to more REC. Nowadays, the REC in Guangdong is the second largest energy consumer, occupying around $15.78 \%$ of the total energy consumption from the end-use perspective in 2017 [32]. With further development of urbanization and industrialization expected, the REC in Guangdong is expected to increase in the future. Although there are many studies on Guangdong seeking to decouple economic growth from carbon emissions or energy consumption [33-35], few of them focus on REC. Thus, the aim of this 
paper is to analyze the decoupling relationship between REC and economic growth (residential income) in-depth in urban and rural Guangdong during 2000-2017. We expect that this study can help Guangdong coordinate their economic growth and REC, as well as provide some important insights and references for researching the REC in China at a national or provincial level. The Tapio decoupling model was applied to analyze the decoupling states in Guangdong urban and rural regions. Then, the main factors (energy structure, energy intensity, per capita income, family size and household) governing the decoupling process are explored by combining the Tapio decoupling model with the LMDI method. Finally, the decoupling effort model is introduced to assess the contribution of each factor to the decoupling.

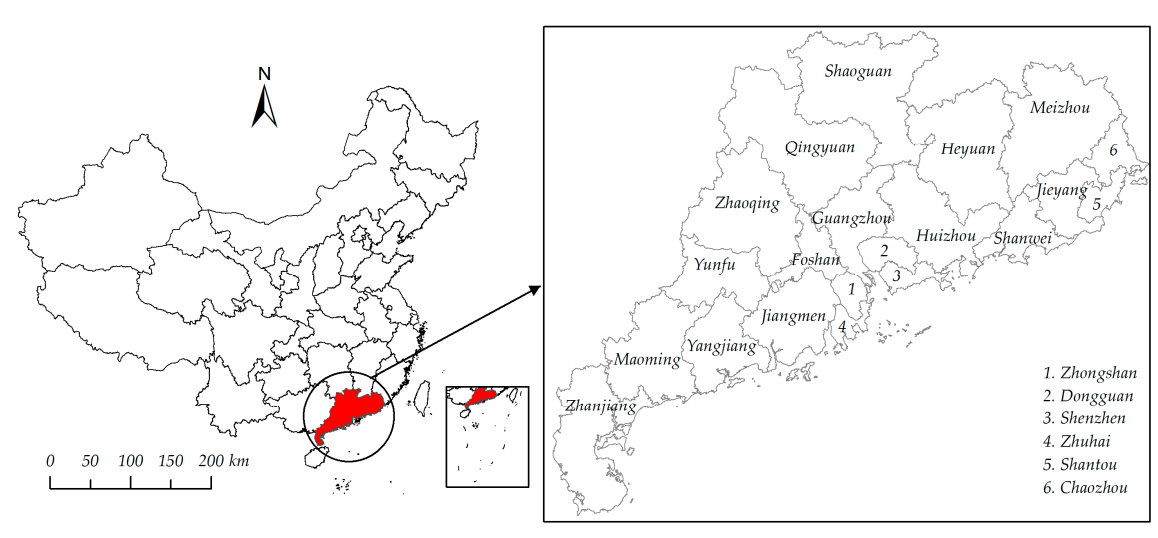

Figure 1. Location of Guangdong province.

The rest of this paper is organized as follows: Section 2 gives the literature review. Section 3 presents the methodology and data description. Section 4 shows the results and discussion. Section 5 displays the main conclusions, policy implications and perspective for future work.

\section{Literature Review}

The term "decoupling" initially originated from the field of physics, meaning a separation of two or more physical variables [1]. Zhang [36] first introduced the concept in the environmental field. Until 2002, the Organization for Economic Co-operation and Development (OECD) categorized decoupling into absolute and relative decoupling [37]. The OECD decoupling indicator was easily influenced by the decoupling elasticity and lacked explicit criteria [2]. Later, Juknys [38] put forward three types of decoupling, namely, the primary, secondary and double decoupling. Tapio [39] built upon that study and studied the EU 15 countries' transportation, to refine the decoupling elasticity and divide the decoupling states into eight logical categories. Since then, the Tapio decoupling model has been widely applied to analyze the dependence of energy consumption or carbon emission on economic growth [40,41]. For instance, the Tapio decoupling model was used by Luo, et al. [42] to analyze the relationship between $\mathrm{CO}_{2}$ emissions and economic growth in the agriculture sectors of 30 Chinses provinces during 1997-2014. Wu, et al. [43] also utilized that method to research the decoupling status between $\mathrm{CO}_{2}$ emissions and economic output in the Chinese construction industry during 2000-2015. Following the Tapio decoupling method, Wang, et al. [3] conducted a comparative study on the decoupling performance between China and the United States.

In fact, the isolated Tapio decoupling method has typically been utilized to quantify the decoupling elasticity, which often failed to capture the effects of environmental externalities and indicate related information for improvement $[43,44]$. As the research in this field developed, many researchers also combined the Tapio decoupling model with the IDA to explore the factors affecting decoupling and assess the effectiveness of real efforts in decoupling progress [40]. For instance, by combining the Tapio decoupling model with the LMDI method, Dong, et al. [45] decomposed the decoupling indicator between energy consumption and economic growth in Liaoning Province from 1995 to 2012 into five 
decoupling indicator effects. They found that the energy intensity effect had a positive influence on decoupling, whereas the effects of economic structure and investment exerted a negative influence on decoupling. Similarly, Zhao, et al. [46] explored the influencing factors of the decoupling of China's industrial growth from $\mathrm{CO}_{2}$ emissions during 1993-2013. The results showed that the investment efficiency was the most important factor accelerating the decoupling, while the investment scale played the most significant role in inhibiting the decoupling. As for assessing the effectiveness of environmental policies in decoupling efforts, focusing on the manufacturing sectors of $14 \mathrm{EU}$ countries, Diakoulaki and Mandaraka [44] assessed the effectiveness of efforts in decoupling the economic growth from $\mathrm{CO}_{2}$ emission by combining the decoupling index with the refined Laspeyres decomposition model. The results suggested that most of these countries made the desirable decoupling efforts. Integrating the decomposition results of LMDI with the decoupling index, Román-Collado, et al. [47] assessed and analyzed the progress in decoupling energy consumption from economic growth in Columbia. Similarly, Wang, et al. [40] evaluated the decoupling efforts of India and China to achieve decoupling during 1990-2015 by employing the decoupling effort model.

As mentioned above, the existing studies on decoupling analyses were mainly conducted from sectoral, national and regional perspectives [3,41]. At the sectoral level, major sectors like agriculture, industry, construction and transportation were studied by using decoupling analyses [42,43,46,48]. Nevertheless, few studies were performed to analyze the decoupling relationship between REC and economic growth, especially the in-depth decoupling analyses of the Chinese residential sector. The main contribution of this paper is to conduct a comprehensive decoupling analysis between the REC and residential income by quantifying the decoupling status, exploring the factors affecting decoupling and measuring the effectiveness of decoupling efforts. We use a representative province in China (i.e., Guangdong) as the case, and conduct a comparative study between urban and rural regions from the perspectives of regional disparity and the urban-rural gap.

\section{Methodology and Data}

\subsection{Decoupling Model}

According to Tapio [39], the decoupling indicator can be defined as:

$$
D=\frac{\Delta E / E^{0}}{\Delta R / R^{0}}
$$

where $D$ denotes the decoupling indicators between REC $(E)$ and residential income $(R)$; the superscript 0 denotes the base year; $\Delta E$ and $\Delta R$ denote the changes of REC and residential income, respectively. $\Delta E / E^{0}$ denotes the growth rate of REC, and $\Delta R / R^{0}$ denotes the growth rate of residential income. The results can produce eight logical possibilities, namely, strong decoupling (SD), weak decoupling (WD), recessive decoupling (RD), strong negative decoupling (SND), weak negative decoupling (WND), expansive negative decoupling (END), recessive coupling (RC) and expansive coupling (EC), as shown in Table 1.

Table 1. The Tapio decoupling model.

\begin{tabular}{cccccc}
\hline Decoupling State & Categories & Abbreviation & $\Delta \mathrm{E} / \mathbf{E}$ & $\Delta \mathbf{R} / \mathbf{R}$ & $\boldsymbol{D}$ \\
\hline Decoupling & Strong decoupling & SD & $<0$ & $>0$ & $(-\infty, 0)$ \\
& Weak decoupling & WD & $>0$ & $>0$ & {$[0,0.8]$} \\
& Recessive decoupling & RD & $<0$ & $<0$ & $(1.2,+\infty)$ \\
\hline \multirow{2}{*}{ Negative decoupling } & Strong negative decoupling & SND & $>0$ & $<0$ & $(-\infty, 0)$ \\
& Weak negative decoupling & WND & $<0$ & $<0$ & {$[0,0.8]$} \\
& Expansive negative decoupling & END & $>0$ & $>0$ & $(1.2,+\infty)$ \\
\hline \multirow{2}{*}{ Coupling } & Expansive coupling & EC & $>0$ & $>0$ & {$[0.8,1.2]$} \\
& Recessive coupling & RC & $<0$ & $<0$ & {$[0.8,1.2]$} \\
\hline
\end{tabular}

Source: Revised from Tapio [39]. 


\subsection{Decomposition Method}

\subsubsection{The LMDI Method}

According to Kaya [49], the REC can be expressed as the extended identity:

$$
E=\sum_{i=1}^{4} E_{i}=\sum_{i=1}^{4} \frac{E_{i}}{E} \times \frac{E}{R} \times \frac{R}{P} \times P
$$

Based on the previous studies [50,51], the REC is usually in the unit of households, which has close correlation with the number of households. In addition, the population does not identify the influences caused by household structure level very well, such as age, gender, education, family size and urban-rural structure, etc. [52]. Hence, we further decompose the population into the family size and household, to make the decomposition results clearer and more reasonable. Thus, Equation (2) becomes:

$$
\begin{aligned}
E & =\sum_{i=1}^{4} E_{i}=\sum_{i=1}^{4} \frac{E_{i}}{E} \times \frac{E}{R} \times \frac{R}{P} \times \frac{P}{H} \times H \\
& =\sum_{i=1}^{4} E S_{i} \times E I \times C P \times F S \times H
\end{aligned}
$$

the variables of which are defined in Table 2.

Table 2. Definition of variables in Equation (3).

\begin{tabular}{ccc}
\hline Variable & Definition & Unit \\
\hline$E$ & Total residential energy consumption (REC) & Ttce \\
$E_{i}$ & REC of fuel $i$ & Ttce \\
$R$ & Residential income & RMB \\
$P$ & Population & $10^{4}$ persons \\
$H$ & The number of households & $10^{4}$ households \\
$E S$ & Share of fuel $i$ in the REC & $\%$ \\
$E I$ & REC per unit of residential income & gce $/ \mathrm{RMB}$ \\
$C P$ & Per capita income of residents & RMB \\
$F S$ & The number of persons per household & person \\
Subscript & $i=1,2,3,4$ for coal, oil, natural gas and electricity & - \\
\hline
\end{tabular}

Based on the LMDI method [53], the changes in the REC $\left(\Delta E_{T O T}\right)$ from the base year 0 to a target year $t$ can be decomposed into five effects:

$$
\Delta E_{T O T}=\Delta E_{t}-\Delta E_{0}=\Delta E_{E S}+\Delta E_{E I}+\Delta E_{C P}+\Delta E_{F S}+\Delta E_{H}
$$

where $\Delta E_{E S}, \Delta E_{E I}, \Delta E_{C P}, \Delta E_{F S}$ and $\Delta E_{H}$ denote the effects of energy structure, energy intensity, per capita income, family size and household, respectively.

The above-mentioned five effects can be calculated as:

$$
\begin{aligned}
\Delta E_{E S} & =\sum_{i} \frac{E_{i}^{t}-E_{i}^{0}}{\ln E_{i}^{t}-\ln E_{i}^{0}} \times \ln \left(\frac{E S_{i}^{t}}{E S_{i}^{0}}\right) \\
\Delta E_{E I} & =\sum_{i} \frac{E_{i}^{t}-E_{i}^{0}}{\ln E_{i}^{t}-\ln E_{i}^{0}} \times \ln \left(\frac{E I^{t}}{E I^{0}}\right) \\
\Delta E_{C P} & =\sum_{i} \frac{E_{i}^{t}-E_{i}^{0}}{\ln E_{i}^{t}-\ln E_{i}^{0}} \times \ln \left(\frac{C P^{t}}{C P^{0}}\right)
\end{aligned}
$$




$$
\begin{aligned}
\Delta E_{F S} & =\sum_{i} \frac{E_{i}^{t}-E_{i}^{0}}{\ln E_{i}^{t}-\ln E_{i}^{0}} \times \ln \left(\frac{F S^{t}}{F S^{0}}\right) \\
\Delta E_{H} & =\sum_{i} \frac{E_{i}^{t}-E_{i}^{0}}{\ln E_{i}^{t}-\ln E_{i}^{0}} \times \ln \left(\frac{H^{t}}{H^{0}}\right)
\end{aligned}
$$

3.2.2. Decomposing the Decoupling Indicator

Combining Equations (1) and (4), the decomposed decoupling indicator can be further extended using Equation (10).

$$
\begin{aligned}
D & =\frac{\Delta E / E}{\Delta R / R}=\frac{\left(\Delta E_{E S}+\Delta E_{E I}+\Delta E_{C P}+\Delta E_{F S}+\Delta E_{H}\right) / E}{\Delta R / R} \\
& =\frac{\Delta E_{E S} / E}{\Delta R / R}+\frac{\Delta E_{E I} / E}{\Delta R / R}+\frac{\Delta E_{C P} / E}{\Delta R / R}+\frac{\Delta E_{F S} / E}{\Delta R / R}+\frac{\Delta E_{H} / E}{\Delta R / R} \\
& =D_{E S}+D_{E I}+D_{C P}+D_{F S}+D_{H}
\end{aligned}
$$

where $D_{E S}, D_{E I}, D_{C P}, D_{F S}$ and $D_{H}$ refer to the energy structure decoupling effect, the energy intensity decoupling effect, the per capita income decoupling effect, the family size decoupling effect and the household effect, respectively.

Particularly, if $\Delta R>0$, the smaller $D$ value represents the greater decoupling process, $D<0$ represents a positive decoupling effect while $D>0$ represents a negative decoupling effect. In contrast, if $\Delta R<0$, a larger $D$ value implies a greater decoupling process [46,54].

\subsection{Decoupling Effort Model}

The decoupling effort model is used to assess the real efforts towards, and effectiveness in achieving, decoupling [44]. The notion of decoupling effort refers to all direct or indirect actions that curb energy consumption or $\mathrm{CO}_{2}$ emission, but which do not hinder economic development [55]. In this study, since per capita income occupies a large proportion of economic activity, the per capita income effect is excluded when assessing the decoupling effort. Thus, the absolute decoupling efforts $\left(\triangle E_{D E}\right)$ undertaken to reduce REC can be defined as the total changes of the energy structure, energy intensity, family size and household effects. Accordingly, the $\Delta E_{D E}$ effect can be expressed as:

$$
\Delta E_{D E}=\Delta E-\Delta E_{C P}=\Delta E_{E S}+\Delta E_{E I}+\Delta E_{F S}+\Delta E_{H}
$$

where the activity effect $\left(\Delta E_{C P}\right)$ is always positive (see Tables A3 and A4); based on Román-Collado, et al. [47], the decoupling effort index can be calculated using Equation (12):

$$
\begin{aligned}
\varphi & =-\frac{\Delta E_{D E}}{\Delta E_{C P}}=-\frac{\Delta E_{E S}+\Delta E_{E I}+\Delta E_{F S}+\Delta E_{H}}{\Delta E_{C P}} \\
& =-\frac{\Delta E_{E S}}{\Delta E_{C P}}-\frac{\Delta E_{E I}}{\Delta E_{C P}}-\frac{\Delta E_{F S}}{\Delta E_{C P}}-\frac{\Delta E_{H}}{\Delta E_{C P}}=\varphi_{E S}+\varphi_{E I}+\varphi_{F S}+\varphi_{H}
\end{aligned}
$$

where $\varphi$ refers to the total decoupling effort index, and $\varphi_{E S}, \varphi_{E I}, \varphi_{F S}$ and $\varphi_{H}$ denote the contributions of the energy structure, energy intensity, family size and household to the decoupling effort index, respectively. There are three types within the index $\varphi$ (strong decoupling effort, weak decoupling effort and no decoupling effort), and the specific description of $\varphi$ is shown in Table 3.

\subsection{Data Description}

Based on data availability, our study period begins in 2000 and ends in 2017. We also divide the REC into urban and rural REC to study the differences in the urban and rural regions of Guangdong. All the REC data are derived from the Energy Balance Sheet of Guangdong Province in the China Energy Statistical Yearbook [30]. The energy unit is expressed as standard coal equivalent consumption in units of $10^{4}$ tce (Ttce). To obtain more accurate results, we consider 10 energy types reported in 
the statistical books. All forms of energy used by residents are divided into four categories (coal, oil, natural gas and electricity). Coal includes raw coal, briquettes and other gases. Oil includes gasoline, kerosene, diesel oil, lubricants and liquefied petroleum gas (LPG). Per capita income, population and family size data are derived from the Guangdong Statistical Yearbook [32]. To eliminate the influence of price change, per capita income is deflated at the 2000 constant price. Notably, all the calculations processes are performed based on the Excel software. In addition, the descriptive statistics of the main variables are based on the SPSS 22.0, of which the specific results are presented in Tables A1 and A2, and Appendix A.

Table 3. Criteria of decoupling effort.

\begin{tabular}{ccl}
\hline & \multicolumn{1}{c}{ State } & \multicolumn{1}{c}{ Description } \\
\hline$\varphi \geq 1$ & Strong decoupling effort & $\begin{array}{l}\text { The total decoupling efforts are larger than the REC } \\
\text { growth governed by the per capita income effect. }\end{array}$ \\
\hline $0<\varphi<1$ & Weak decoupling effort & $\begin{array}{l}\text { The total decoupling efforts are smaller than the REC } \\
\text { growth governed by the per capita income effect. }\end{array}$ \\
\hline$\varphi \leq 0$ & No decoupling effort & $\begin{array}{l}\text { The total decoupling efforts contribute to the REC } \\
\text { growth and have no effect on decoupling. }\end{array}$ \\
\hline
\end{tabular}

Source: Revised from Diakoulaki and Mandaraka [44] and Román-Collado, et al. [47].

\section{Results and Discussion}

\subsection{The Situation of REC in Urban and Rural Guangdong}

\subsubsection{The Total REC in Urban and Rural Guangdong}

Figure 2a shows that the urban REC increased from 585.84 Ttce in 2000 to 2017.77 Ttce in 2017, with a growth rate of $7.55 \%$ and an annual average amount of 84.23 Ttce. The increase in REC in urban Guangdong may be due to the spectacular growth in oil and electricity usage. According to the previous studies [31,56,57], urban residents had the capacity and were more likely to pursue luxurious and higher-quality lifestyles as the economy and urbanization developed, thus resulting in the growing popularity of energy-intensive electric appliances and private transport. For instance, the ownership of family cars, air conditioners, computers and mobile telephones per 100 urban households in 2017 was 21.6-fold, 1.7-fold, 3.4-fold and 4.1-fold more than that in 2000 (Figure 2c), respectively.
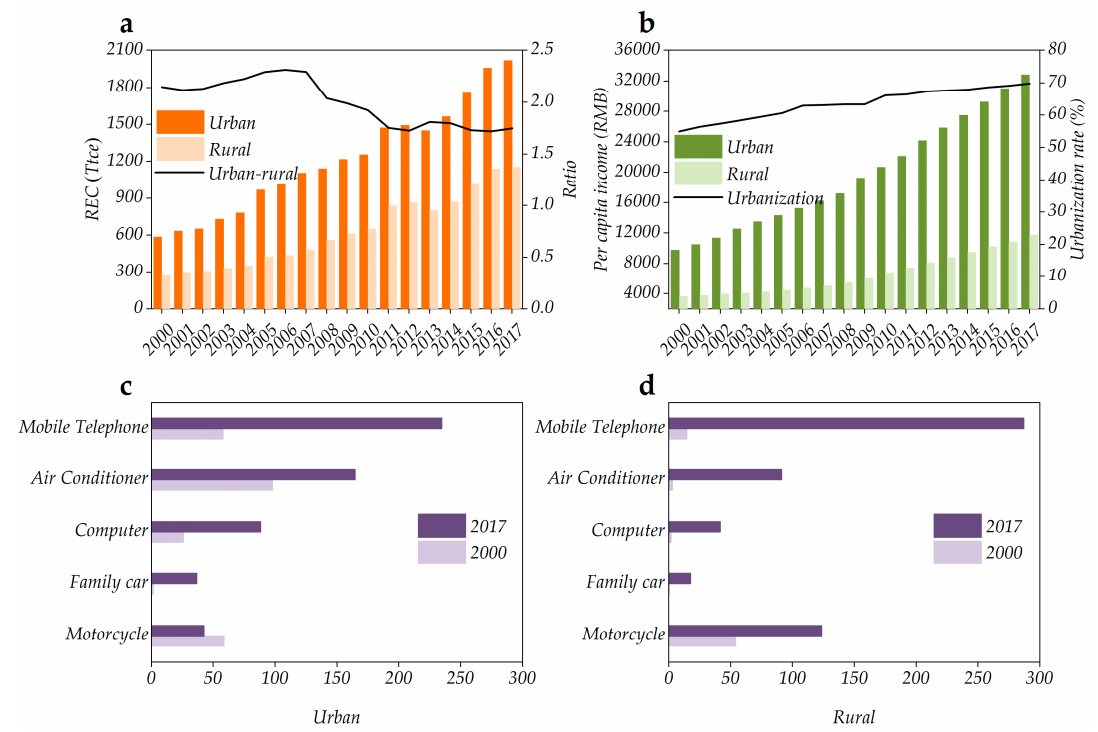

Figure 2. Trends of REC and related indicators in urban and rural Guangdong during 2000-2017. (a) Total REC and the ratio of urban to rural. (b) Per capita income and urbanization rate. (c) Ownership of major durable consumer goods per 100 urban households. (d) Ownership of major durable consumer goods per 100 rural households. 
The rural REC also exhibited a growth trend and increased quicker than urban REC over the study period (Figure 2a). It rose from 272.46 Ttce in 2000 to 1153.70 Ttce in 2017, with an annual average growth rate of $8.86 \%$ and amount of 51.84 Ttce. This increase of REC could be explained by the following reasons. First, the rural economy experienced a spectacular development, which led to more energy use. Second, rural residents had an increased demand for electric appliances and private transport as living standards improved, which led to the higher consumption of electricity and oil products. For instance, the ownership of motorcycles, family cars, air conditioners, computers and mobile telephones per 100 rural households in 2017 was 2.3-fold, 50.2-fold, 29.9-fold, 21.3-fold and 19.8-fold more than that in 2000 (Figure 2d), respectively. Overall, both the urban and rural REC showed an increase trend, which was consistent with many related studies $[7,8,17]$.

Figure 2a also shows the gap of REC in urban and rural Guangdong. The ratio of urban-rural decreased from 2.15 in 2000 to 1.75 in 2017, converging on the interval 1.7-2.4 in most years. The urban-rural ratio underwent a trend of increase (2000-2006) and then decrease (2006-2017). During 2000-2006, the urbanization rate of Guangdong increased from 55.0\% to $63.0 \%$ (Figure $2 b$ ), implying that urban residents owned more energy equipment and consumed more commercial energy than rural residents. The reason for the reduction in the urban-rural gap during 2006-2017 might be explained as follows. Rural residents were able to purchase more appliances and utilize private transport as the rural economy developed, which required more energy use. Moreover, it could be easily observed that the urban-rural ratio was always more than 1.0, which result was similar for Shandong and Jiangsu [7,17]. This phenomenon mainly resulted from the urban-rural duality in China in the long term $[19,58]$.

\subsubsection{The Energy Structure of REC in Urban and Rural Guangdong}

The changes in the energy structure of REC in urban and rural Guangdong are presented in Figure $3 \mathrm{a}, \mathrm{b}$ respectively. As shown in Figure $3 \mathrm{a}$, oil and electricity were the main energy sources for urban residents during 2000-2017, accounting for over $92 \%$. This could be due to the growing popularity of electrical appliances and private transport. Over the study period, the share of oil always ranked first, followed by electricity, coal and natural gas. It was noteworthy that the share of oil presented a moderate declining trend, decreasing to $61.11 \%$ in 2017 from $69.82 \%$ in 2000 , whereas the share of electricity increased from $23.55 \%$ to $34.40 \%$ between 2000 and 2017. Based on these trends of oil and electricity above-mentioned, oil may still dominate the energy structure of REC for a long time in the future. The coal share presented a decline trend over time, decreasing to $3.55 \%$ in 2017 from $6.62 \%$ in 2000 . The share of natural gas remained relatively lower, increasing from $0.28 \%$ in 2006 to $0.95 \%$ in 2017 . With the development of the economy and the improvement of residents' living standards, the share of coal will further shrink, and may be exceeded by natural gas in the future.

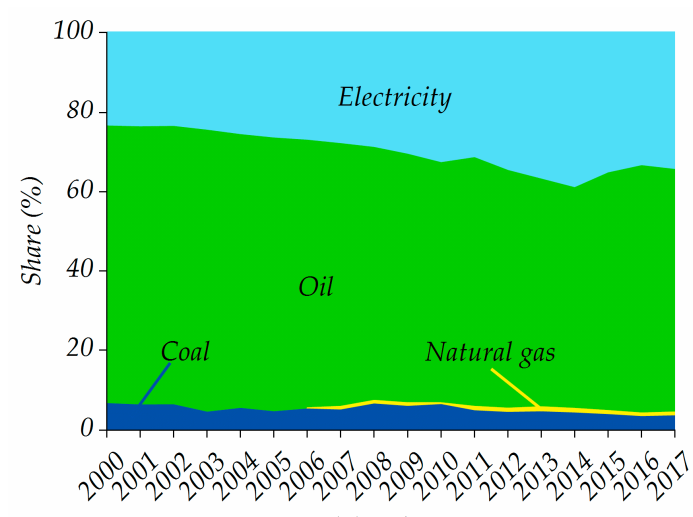

(a) Urban

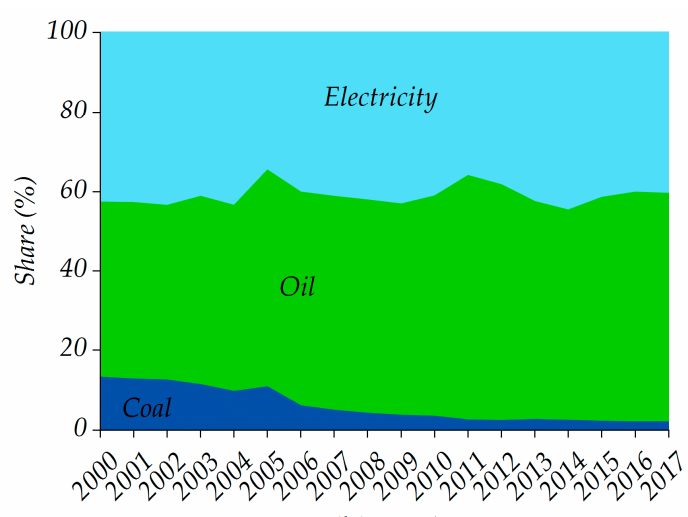

(b) Rural

Figure 3. Trends of the energy structure of REC in urban and rural Guangdong during 2000-2017.

(a) Urban. (b) Rural. 
With respect to rural Guangdong, natural gas was not found to be significant in the REC according to the Guangdong Statistical Yearbook [32]. Therefore, we do not consider it. Figure 3b shows that the share of oil always ranked first, followed by electricity and coal. Since 2002, the gap between the uses of oil and electricity widened. The share of oil increased from $44.11 \%$ in 2002 to $57.59 \%$ in 2017, while the share of electricity decreased from $43.37 \%$ in 2002 to $40.36 \%$ in 2017 . This may be explained by the fact that the increase in REC from private transport (motorcycles, family cars, etc.) was more than that from electric appliances in rural regions. In addition, the share of coal always showed a declining trend over the study period, except in 2005 , decreasing to $2.05 \%$ from $13.20 \%$. In fact, not only Guangdong, but also Jiangxi [58], Shanxi [51], Shandong [17], Jiangsu [7] and the national level [8] showed a decreased share of coal, while the share of oil and electricity increased.

\subsubsection{The Energy Intensity of REC in Urban and Rural Guangdong}

Figure 4 shows the changes of the energy intensity of REC in the Guangdong urban and rural regions. Here, we define the energy intensity as the ratio of REC to residential income, which reflects the energy efficiency. Over the study period, the trend of energy intensity of REC always presented a declining trend, except for 2005, 2011, 2014, 2015 and 2016, decreasing from 12.61 gce/RMB in 2000 to 7.88 gce/RMB in 2017 , with an annual average decrease rate of $2.80 \%$, indicating that the energy efficiency of REC improved in urban Guangdong. This could be due to the improvement of technology and energy label management methods for electric appliances and transport tools.

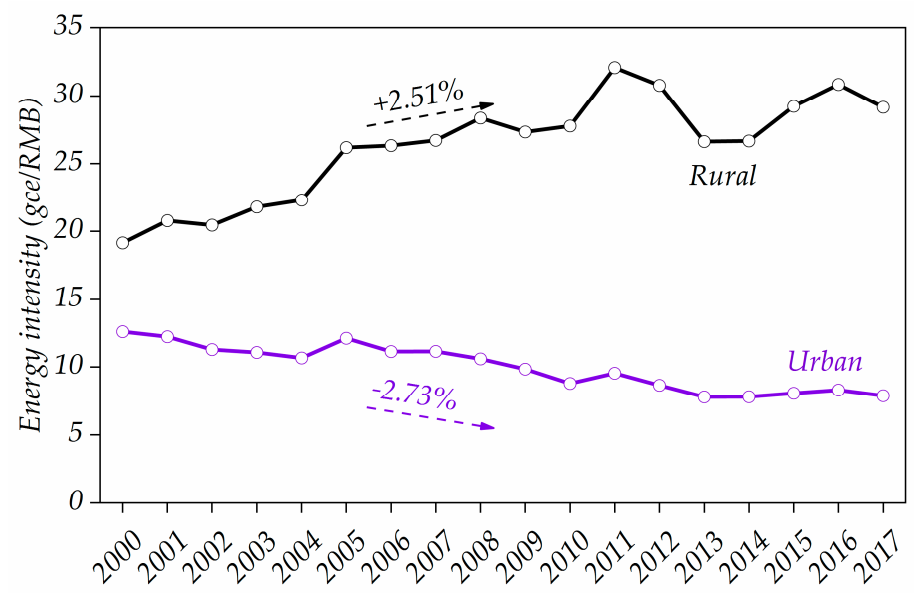

Figure 4. Trends of energy intensity in urban and rural Guangdong during 2000-2017.

With respect to rural Guangdong, the energy intensity of REC shows an opposite trend. It rose from 19.15 gce/RMB in 2000 to 29.18 gce/RMB in 2017, with an annual average growth rate of $2.51 \%$, suggesting that the energy efficiency of REC did not improve. The increase in the energy intensity could be explained by the following reasons. First, some of the rural residents had less awareness of energy-saving and environmental protection than urban residents. Second, traditional biomass was outpaced by the commercial energy use modes over time [7]. In fact, the trends of the energy intensity of REC in urban and rural regions in Guangdong were similar to those of the related studies [8,17]. For example, Zhang and Bai [17] found that the energy intensity of residential energy consumption increased for rural Shandong, while it decreased for urban Shandong over the study period.

\subsection{Decoupling States in Guangdong Urban and Rural Regions}

The indicators of decoupling between the REC and residential income for the Guangdong urban and rural regions during 2000-2017 are given in Figure 5a,b, respectively. As shown in Figure 5a, only four decoupling states (WD, EC, END and SD) occurred because the change rates of residential income were positive over the study period. More specifically, WD occurred in most years $(52.94 \%$ of 
the whole period), indicating that residential income increased a little faster than the REC. EC appeared when there was no significant decoupling relationship between the REC and residential income, i.e., 2002-2003, 2006-2007 and 2013-2014 (17.65\% of the whole period). END happened during 2004-2005, 2010-2011 and 2014-2016 (23.53\% of the whole period), indicating that the REC grew faster than residential income. SD represented the ideal decoupling state, which only occurred during 2012-2013 (5.88\% of the whole period). In summary, the decoupling state showed WD (0.54) in urban Guangdong, implying that the REC depends less on residential income. However, the urban regions' desirable decoupling rates (WD and SD) were still less than $60 \%(58.82 \%=52.94 \%+5.88 \%)$, which indicates their decoupling states have great space for improvement.

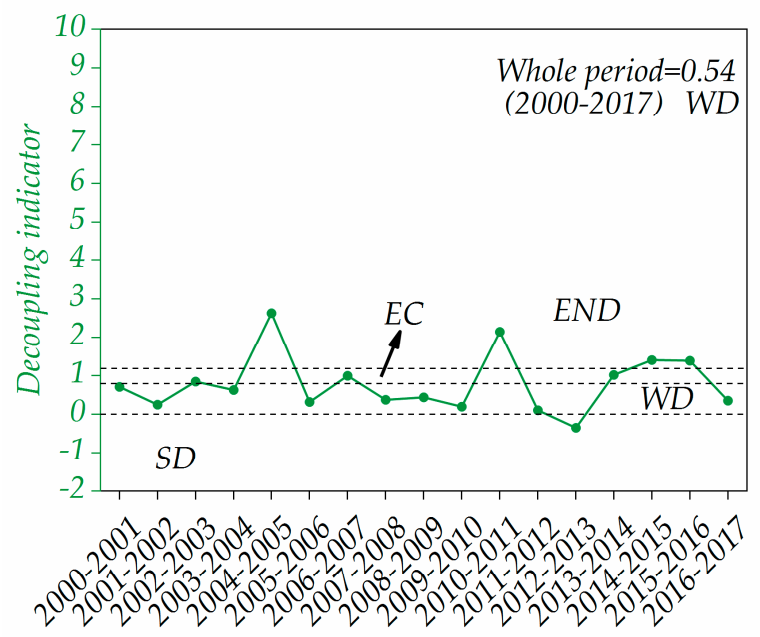

(a) Urban

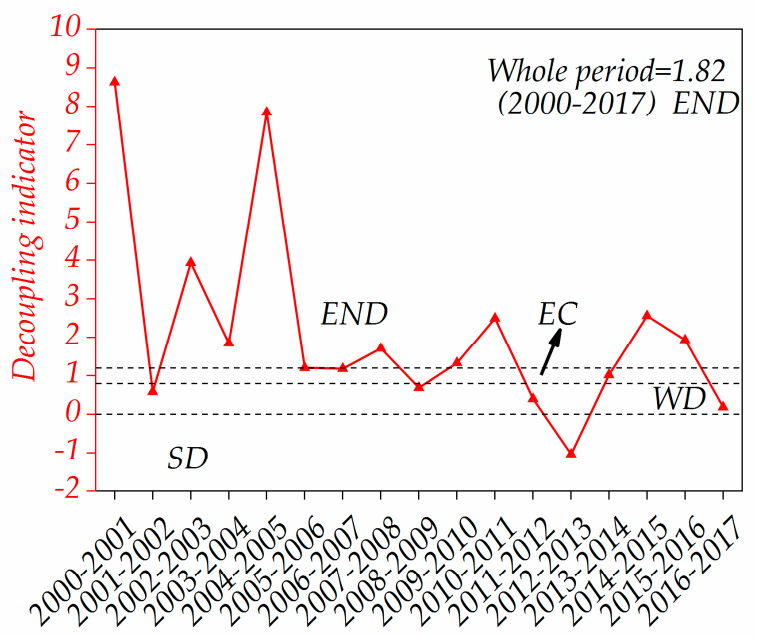

(b) Rural

Figure 5. Decoupling states in Guangdong urban and rural regions during 2000-2017. (a) Urban. (b) Rural.

Similarly, there were also four kinds of decoupling states in Guangdong rural regions: END, WD, EC and SD (Figure 5b). However, there were some differences between urban and rural regions. END occurred most often, e.g., during 2000-2001, 2002-2006, 2007-2008, 2009-2011 and 2014-2016, accounting for $58.82 \%$ of the whole period. EC only appeared during 2006-2007 and 2013-2014 ( $11.76 \%$ of the whole period). In addition, rural regions experienced less WD than urban regions, which disconnectedly appeared during 2001-2002, 2008-2009, 2011-2012 and 2016-2017 (23.53\% of the whole period). SD also only took place during 2012-2013 (5.89\% of the whole period), which was consistent with that seen in urban regions. Overall, rural regions' decoupling states showed END (1.82), suggesting that the REC still depends on residential income. Therefore, it could be concluded that the urban regions' decoupling states were more ideal than that of the rural regions. Compared with urban regions, rural regions' desirable decoupling rates were less than $30 \%(29.42 \%=23.53 \%+5.89 \%)$, indicating that these regions' decoupling states also have great potential to enhance. Therefore, more attention and effective efforts should be paid to accelerating the rural regions' decoupling processes in the future.

\subsection{Drivers Affecting the Decoupling in Guangdong Urban and Rural Regions}

Following Equations (3)-(9), we quantified the contributions of each factor governing the REC in the urban and rural regions of Guangdong during 2000-2017, which are listed in Tables A3 and A4, respectively. An important step of our study is to further explore the key drivers affecting the decoupling after analyzing the decoupling states. With reference to previous studies [1,59], we combine the Tapio decoupling model with the LMDI method to identify the factors affecting the decoupling process. We decomposed the decoupling indicator using Equation (10), and the corresponding decomposition 
results of the decoupling indicators in urban and rural Guangdong during 2000-2017 are presented in Figure 6a,b, respectively.

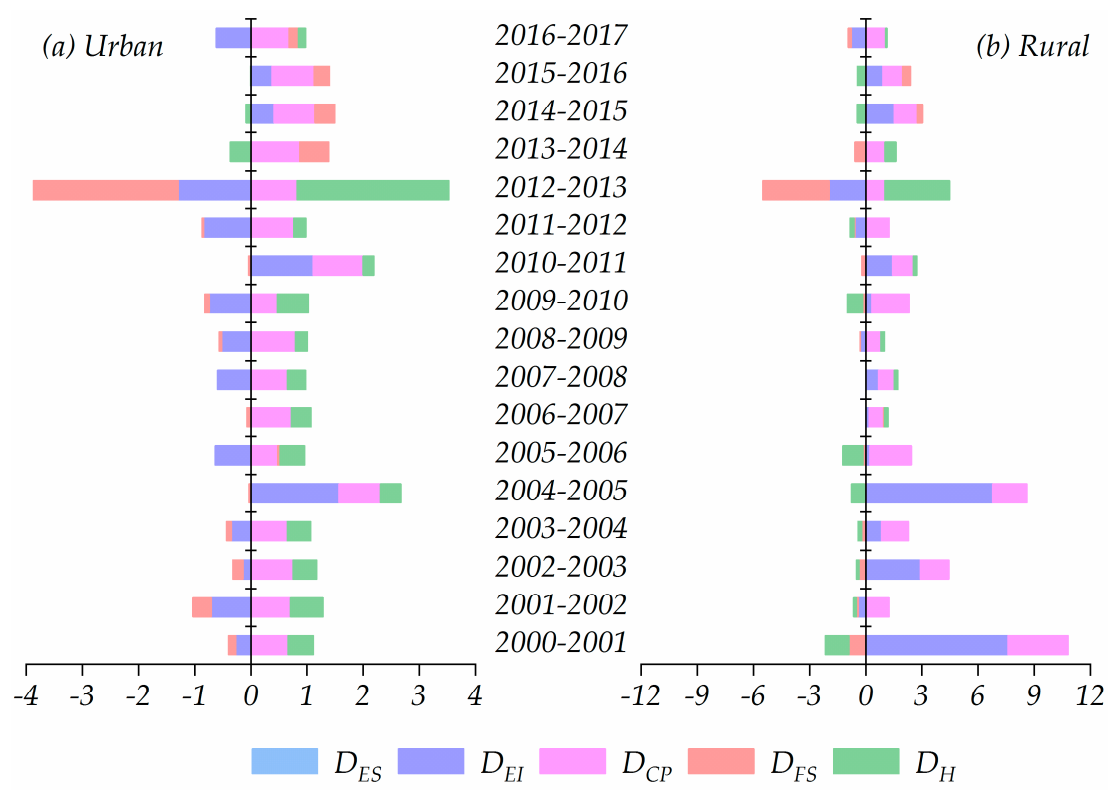

Figure 6. Decomposition of decoupling in Guangdong urban and rural regions during 2000-2017.

(a) Urban. (b) Rural.

Figure 6a shows that the energy intensity effect played the most important role in promoting the decoupling process in urban Guangdong, followed by the family size effect. Over the study period, the energy intensity decoupling indicator was always negative, except for in 2005, 2007, 2011, 2014, 2015 and 2016, indicating that improving the energy efficiency can be an effective pathway to achieving decoupling. In addition, the change of energy intensity could explain why the energy intensity effect inhibited the decoupling in these six years (Figure 4). Family size effect played a more stable role in accelerating the decoupling process over the study period. Figure 7 shows that the urban family size in Guangdong shrank to 2.87 persons in 2017 from 3.57 persons in 2000, representing an annual decrease rate of $1.29 \%$. To the best of our knowledge, China (including Guangdong) carried out the long-term "one-child population policy", which led to a decrease in the family size of urban households [60]. With the development of the urban economy and the change of social concepts, urban residents' family planning intentions declined, while the rates of single, divorced and unmarried people increased. All these factors also shrank the urban family size, spawning the increase of one-person households, two-person households, DINK households (Double Income, No Kids), single-parent households and empty nest households (consisting of one or two elders). The smaller family size households thus consumed less REC than larger family size households [51], which promoted the decoupling process. It should be noted that a rebound of the urban family size has recently occurred and it has slightly increased to 2.87 persons in 2017 from 2.59 persons in 2013, resulting from the release of the "selective two-child policy" and the "universal two-child policy" in China (including Guangdong) at the end of 2013 and 2015, respectively. Specifically, on 15 November 2013, the Chinese government decided to release the selective-child policy to contend with the aging and population structure imbalance problems. This policy allows that the only-child couples can bear two children. On 27 March 2014, Guangdong government formally implemented this policy. On 29 October 2015, the Chinese government further put forward the universal two-child policy on the basis of the selective two-child policy. The universal two-child policy means that all couples are allowed to bear two children, which was formally implemented on January 1, 2016. This could explain why the family size effect restricted the decoupling during 2013-2017. 


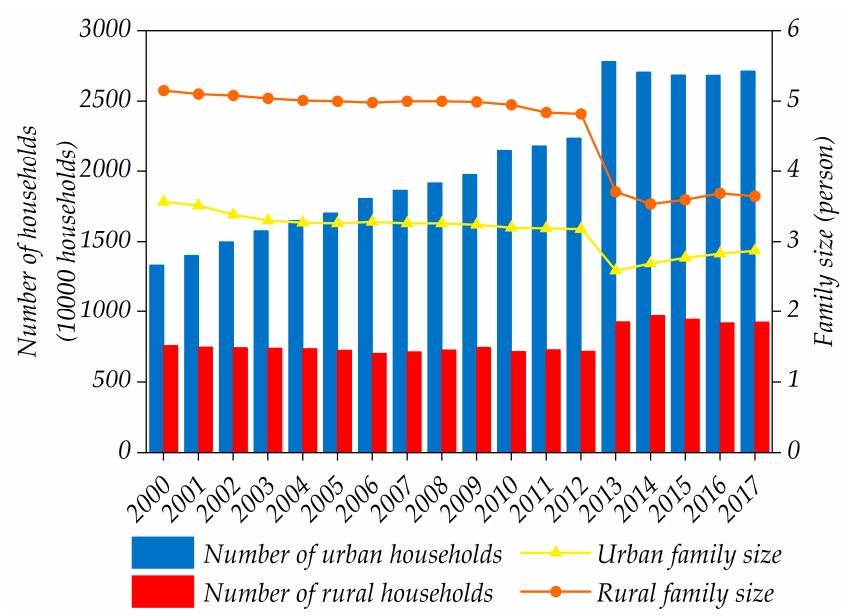

Figure 7. The number of households and family size in Guangdong urban and rural regions during 2000-2017.

Figure 6a shows that the per capita income effect played the most negative role in the decoupling process in urban Guangdong, followed by the effects of household and energy structure. The per capita income effect always inhibited the decoupling process over the study period. This could be explained by the fact that the per capita income continuously increased from RMB 9761.51 in 2000 to RMB 32836.44 in 2017 as the urban economy rapidly developed, representing an annual growth rate of $7.40 \%$ (Figure $2 b$ ). Here, we define the ratio of population to family size as the number of households. Figure 7 shows that the number of urban households reached 27.18 million in 2017 from 13.33 million in 2000, with an annual growth rate of $4.28 \%$, which was due to the development of urbanization (Figure $2 b$ ). As the most developed province in China, Guangdong attracted a large number of rural residents from Guangdong or other provinces to migrate to the urban regions, accelerating the urbanization process and directly increasing the number of urban households [8,51]. More households yielded more requirements for energy use and caused an increase of REC, which in turn inhibited the decoupling. The energy structure effect played a relatively marginal role in inhibiting the decoupling during 2000-2017. This could be explained by energy endowments in China (including Guangdong) [3,58], i.e., inexpensive prices and a high supply of coal, and a relative lack of oil and natural gas. Thermal power accounted for the largest proportion of electricity in Guangdong, though it has been dominated by coal in the long term.

The decomposition results of the decoupling indicators in rural Guangdong are shown in Figure 6b. It could be observed that the effects of family size and household were the two main factors accelerating the decoupling process. Over the study period, the decoupling indicator of family size was always negative (except 2006-2007 and 2014-2016), suggesting that the reduction of family size promoted the decoupling. As shown in Figure 7, the rural family size fell to 3.65 persons in 2017 from 5.15 persons in 2000 , with an annual decrease rate of $2.05 \%$. The reasons for rural family size decline were similar to those in the urban regions. Notably, the family size effect exerted a negative impact on the decoupling during 2014-2016. This was because the family size increased from 3.54 persons to 3.69 persons between 2014 and 2016 with the implementation of the selective and universal two-child policies. Compared with the urban regions, the effect of household played a positive role in promoting decoupling in most years. The reason for this may be the rapid urbanization, which accelerated the mobility of rural residents to urban regions. However, the household effect played a negative role in inhibiting the decoupling in 2007, 2008, 2009, 2011, 2013, 2014 and 2017. This could be explained by the following reasons. First, many factories and enterprises in Guangdong urban regions closed down due to the 2008 financial crisis, making many rural laborers return to rural regions. Therefore, the number of rural households increased during 2007-2009 (Figure 7), which led to more REC and restricted decoupling during 2007-2009. In addition, the change trend of the number of rural households could explain why the household effect exerted a negative influence on decoupling during 2013-2014 and 2017 (Figure 7). 
Figure $6 \mathrm{~b}$ shows that the decoupling indicator of per capita income was always within the interval 0.8-3.2 over the study period, suggesting that the per capita effect was the most critical and stable factor inhibiting the decoupling process in rural Guangdong, followed by the energy intensity effect and the energy structure effect. As the rural economy has developed, the per capita income for rural residents continuously increased from RMB 3654.48 in 2000 to RMB 11741.49 in 2017 (Figure 2b), with an annual average growth of $7.26 \%$. The energy intensity effect exerted a negative influence on the decoupling in most years, excluding five years (2002, 2009, 2012, 2013 and 2017). The change of energy intensity of rural REC could explain why the energy intensity effect promoted the decoupling process in these five years (Figure 4). In view of the energy structure effect, it also played a minor role in inhibiting the decoupling process overall, which was consistent with urban regions.

\subsection{Analysis of Decoupling Efforts in Urban and Rural Guangdong}

Using Equations (11)-(12), the decoupling effort indices of REC in urban and rural Guangdong over time were calculated in Figure 8a,b, respectively. The tendency of the total decoupling effort index in urban Guangdong always fluctuated between -1 and 1, except during 2004-2005, 2010-2011 and 2012-2013 (Figure 8a). Specifically, the total decoupling effort index was often less than 0, i.e., in 2000-2001, 2002-2003, 2004-2005, 2006-2007, 2010-2011 and 2013-2016, in a no decoupling effort state, indicating that the decoupling policy failed to achieve its intent. During most years in the period 2005-2013, the total decoupling effort index always remained within the interval 0-1, in a weak decoupling effort state, showing that the decoupling efforts of the four factors promoting decoupling were weaker than the per capita income decoupling effect. A strong decoupling effort showed that the decoupling effort policy had a positive influence on achieving decoupling, but it only occurred during 2012-2013. Of the four effects on the decoupling effort index defined above, the energy intensity decoupling effect played a dominant role in promoting decoupling in most years, i.e., it was highly effective in accelerating the decoupling between the REC and residential income by improving energy efficiency. The decoupling effort state of the family size factor shifted from a weak decoupling effort state (2000-2012) to a strong decoupling effort state (2012-2013), then switched to a no decoupling effort state (2013-2017), indicating that effective efforts were made in the family size area for achieving decoupling before 2013, but no efforts for decoupling were made after 2013. Though energy structure was in a weak decoupling effort state overall, the decoupling effort index was relatively small, and almost 0 . This indicates that the decoupling efforts in the area of energy structure were not significant enough, and it has large unrealized potential for achieving decoupling. However, the decoupling effort index of the household factor was always less than 0 in most years, in a no decoupling effort state.

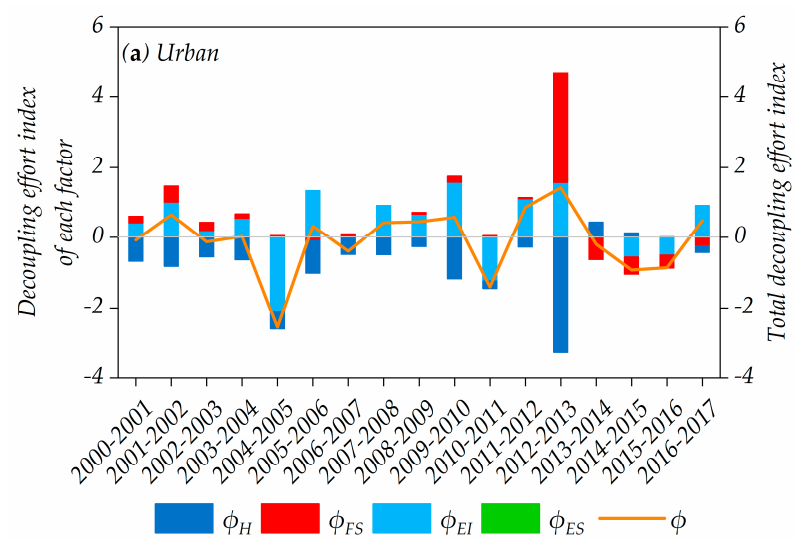

Figure 8. Cont. 


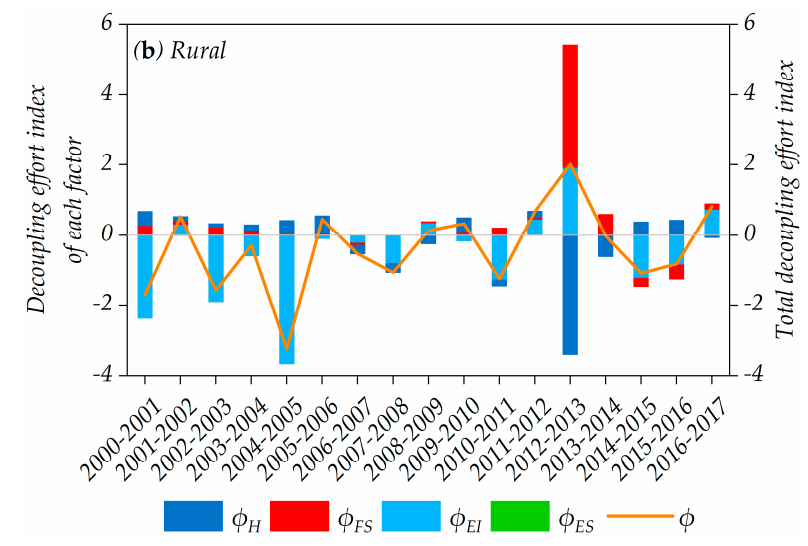

Figure 8. Trends of the decoupling effort index in urban and rural Guangdong. (a) Urban. (b) Rural.

In most years of the study period, the total decoupling effort index in rural Guangdong fluctuated and always remained within the interval -2 to 1 (Figure $8 \mathrm{~b}$ ). In detail, the total decoupling effort index was always less than 0 during 2000-2008, 2010-2011 and 2013-2015 (except 2001-2002 and 2005-2006), in a no decoupling effort state, indicating that the decoupling effort policies had no effect on the decoupling. For the rest of the years (except the biggest value of 2.01 during 2012-2013), the total decoupling effort index was between 0 and 1 , in a weak decoupling effort state, implying that the decoupling policies were slightly effective. Over the study period, the decoupling effort index of family size converged on the interval 0 to 1 (excluding during 2006-2007, 2012-2013 and 2014-2016) with an average value of 0.28 , in a weak decoupling effort state, indicating that family size stably promoted decoupling. The decoupling effort index of household was greater than 0 and less than 1 in many years of the study period, in a weak decoupling effort, indicating that household promoted decoupling overall. However, it was not more stable than family size. To be specific, the decoupling effort index of household remained within the interval 0-1 during 2000-2006, 2009-2010, 2011-2012 and 2014-2015, in a weak decoupling effort state. For the rest of the years, except 2012-2013 (which reached the peak value of -3.40 ), it was in a no decoupling effort state. In terms of energy structure, its decoupling effort index was also relatively small and almost 0 , in a weak decoupling effort, which was consistent with urban regions. However, the decoupling effort index of energy intensity was less than 0 in most years, in a no decoupling effort state, which indicated that the energy intensity had no effect on decoupling overall.

\section{Conclusions and Policy Implications}

\subsection{Main Conclusions}

Presently, the REC has become the second largest source of energy consumption in China. However, previous efforts paid little attention to studying the decoupling relationship between the REC and economic growth. This paper conducted comparative decoupling analysis between REC and economic growth (residential income) in urban and rural Guangdong during 2000-2017. First, we overviewed the situation of the REC in Guangdong urban and rural regions. Secondly, the Tapio decoupling indicator was used to analyze the decoupling status. We then further decomposed the decoupling index to explore the main factors affecting the decoupling process by combining the Tapio decoupling model with the LMDI method. Finally, the decoupling effort model was used to assess the effectiveness of the efforts towards achieving decoupling in urban and rural Guangdong. The main results are as follows:

Over the study period, the REC showed a similar trend of rapid increase in both urban and rural regions of Guangdong, as the residents' living standards improved. However, the growth rate of the rural REC (8.86\%) was faster than that of the urban REC (7.55\%). The urban-rural gap of REC became narrow, though it was more than 1.0 for most years. The energy structure of the REC was dominated 
by oil in both urban and rural regions. In terms of the energy intensity of REC, overall, it decreased in urban regions, whereas it increased in rural regions.

Both urban and rural regions experienced four kinds of decoupling states: WD, EC, END and SD. WD occurred in most years (52.94\% of the whole period) for urban regions, while END was dominant for nearly $60 \%$ of the whole period for rural regions. Overall, the decoupling state in urban regions was more ideal overall than that in rural regions, representing a WD (0.54) and an END (1.82), respectively.

Over the study period, the per capita income effect was the leading factor restricting the decoupling, followed by the household and energy structure effects, while the effects of energy intensity and family size accelerated the decoupling process in urban regions. In rural regions, per capita income was the biggest contributor to inhibiting the decoupling, followed by the effects of energy intensity and energy structure. Conversely, the household and family size effects had a positive effect on the decoupling process. Overall, the decoupling efforts in urban regions were mainly due to the improvement of energy efficiency, whereas the decoupling efforts in rural regions were mainly due to the reduction in family size.

\subsection{Policy Implications}

First, the per capita income effect was the biggest contributor to inhibiting the decoupling process in both urban and rural regions of Guangdong. As the most developed province in China, it is not wise for Guangdong to restrain residential consumption to achieve the decoupling, because consumption is the important impetus for economic growth, while a high-energy consumption model can no longer satisfy the needs of residents and the government for an environmentally friendly society. Therefore, the Guangdong government should seek a trade-off between economic growth and energy consumption. Increasing the investment and $R \& D$ (research and development) in products and services to foster new residential consumption spots can be a smart choice, such as smart home appliances, new energy vehicles, low energy consumption public transport and green residential buildings. Additionally, macro-control policies can also be applied to cut down the corresponding REC. For example, taxes could be increased for energy-intensive appliances, while subsidies and tax reductions could be granted for energy-saving appliances.

Secondly, the energy intensity effect made effective decoupling efforts and promoted decoupling in urban regions, whereas it made no decoupling efforts and inhibited the decoupling in rural regions. This suggests that the energy efficiency in rural regions is lower than that in urban regions. Thus, it is imperative to improve energy efficiency in rural regions so as to promote decoupling. On one hand, Guangdong rural regions can further eliminate the usage of outdated energy types (e.g., straw, firewood) to improve the energy efficiency of REC. On the other hand, the Guangdong government at all levels should actively guide rural residents to shift their lifestyles or behaviors to a low-carbon pattern. The specific measures can include public propaganda and education as well as drafting corresponding laws. Furthermore, rural residents should also enhance their awareness of energy conservation and environmental protection in their daily life.

Thirdly, the family size effect played a positive role in the decoupling process in both urban and rural regions. However, the decoupling effort of family size shifted from a weak decoupling effort state to a no decoupling effort state after 2013, indicating that the effect of family size on achieving decoupling will be weaker in the future. Presently, the family size is two to three persons and three to four persons in urban and rural Guangdong, respectively. To the best of our knowledge, the continuously shrinking family size may cause a series of unforeseen future problems, such as labor shortages and pension burdens, etc., while the expansion of family size will put the environment under strain. Therefore, the government should evaluate the population carrying capacity of Guangdong's environment and resources, and put more effort into further adjusting the population structure by drafting reasonable and adaptive population policies.

Finally, the energy structure effect played only a minor role in inhibiting the decoupling process in both urban and rural Guangdong, suggesting that the energy structure of the REC was less than 
ideal and had enormous room for achieving the desired decoupling state. Thus, the Guangdong government should devote itself to further optimizing the energy structure and supporting related innovative energy technologies. Specifically, it should be reducing the proportion of thermal power and vigorously developing renewable and clean energy types, e.g., natural gas, nuclear technology, wind power, solar thermal power generation, hydro power, etc.

\subsection{Limitations and Perspectives for Future Work}

Some limitations are inherent within our study. We only researched the direct REC, while the indirect REC was excluded. This underestimates the total REC in Guangdong. Thus, further research is needed to analyze the indirect REC with more effective methods. Furthermore, both urbanization and economic growth had a great impact on REC, while this study mainly explored the relationship between REC and economic growth (residential income). Therefore, a future research direction will be to investigate the relationship between urbanization and REC in more detail.

Author Contributions: Conceptualization, Y.Y. and J.J.; methodology, Y.Y. and M.J.; software, Y.Z.; validation, D.X. and J.J.; formal analysis, M.J.; writing—original draft preparation, Y.Y.; writing—review and editing, A.T.D. and J.J.; visualization, Y.Y. and D.X.; supervision, J.J.; funding acquisition, J.J. All authors have read and agreed to the published version of the manuscript.

Funding: This research was supported by National Natural Science Foundation of China (71473113), and the Research Project of Humanities and Social Sciences in Jiangxi's Universities (GL19225).

Acknowledgments: The authors are grateful for the anonymous reviewers and editor for their detailed comments and valuable suggestions to improve the quality of this article.

Conflicts of Interest: The authors declare no conflict of interests.

\section{Appendix A}

Descriptive statistics of the main variables: The descriptive statistics are usually utilized to describe the characteristics of data. In this paper, we chose some main variables to perform descriptive statistics analysis in urban and rural Guangdong. Specifically, theses variables include REC (residential energy consumption), P (population), CP (per capita income), $\mathrm{H}$ (the number of households), $\mathrm{F}$ (Family size) and $\mathrm{EI}$ (energy intensity). In addition, $\mathrm{ES}_{1}, \mathrm{ES}_{2}, \mathrm{ES}_{3}$ and $\mathrm{ES}_{4}$ refer to the share of coal, oil, electricity and natural gas within REC, reflecting the energy structure. Based on SPSS 22.0, the results of the descriptive statistics of these main variables in urban and rural Guangdong are shown in Tables A1 and A2. The index Mean was used to assess the central tendency of variables, and the indices Maximum, Minimum, Standard Deviation and Variance are employed to show the dispersion. Besides these, we introduce the indices Skewness and Kurtosis to present the distributions of discrete variables.

Table A1. Descriptive statistics of the main variables in urban Guangdong.

\begin{tabular}{cccccccc}
\hline Variables & Mean & $\begin{array}{c}\text { Standard } \\
\text { Deviation }\end{array}$ & Variance & Skewness & Kurtosis & Maximum & Minimum \\
\hline REC & 1211.046 & 447.608 & $200,352.827$ & 0.279 & -0.881 & 2017.767 & 585.845 \\
P & 6342.216 & 999.166 & $998,332.196$ & -0.162 & -1.416 & 7801.547 & 4757.517 \\
CP & $19,638.690$ & 7384.597 & $54,532,266.901$ & 0.385 & -1.134 & $32,836.439$ & 9761.570 \\
H & 2050.577 & 494.443 & $244,474.095$ & 0.259 & -1.305 & 2784.701 & 1332.638 \\
FS & 3.154 & 0.281 & 0.079 & -0.726 & -0.400 & 3.570 & 2.590 \\
EI & 0.100 & 0.017 & 0.000 & 0.024 & -1.470 & 0.126 & 0.078 \\
SS $_{1}$ & 0.051 & 0.010 & 0.000 & 0.049 & -1.229 & 0.066 & 0.034 \\
$\mathrm{ES}_{2}$ & 0.643 & 0.048 & 0.002 & -0.126 & -1.236 & 0.709 & 0.556 \\
$\mathrm{ES}_{3}$ & 0.300 & 0.049 & 0.002 & 0.190 & -1.221 & 0.390 & 0.236 \\
$\mathrm{ES}_{4}$ & 0.009 & 0.003 & 0.000 & -1.429 & 1.624 & 0.012 & 0.003 \\
\hline
\end{tabular}


Table A2. Descriptive statistics of the main variables in rural Guangdong.

\begin{tabular}{cccccccc}
\hline Variables & Mean & $\begin{array}{c}\text { Standard } \\
\text { Deviation }\end{array}$ & Variance & Skewness & Kurtosis & Maximum & Minimum \\
\hline REC & 633.995 & 295.348 & $87,230.643$ & 0.442 & -1.109 & 1153.698 & 272.464 \\
P & 3576.960 & 157.632 & $24,847.901$ & 0.430 & -0.874 & 3892.514 & 3367.454 \\
CP & 6606.573 & 2670.906 & $7,133,740.562$ & 0.638 & -0.979 & $11,741.488$ & 3654.480 \\
H & 786.449 & 96.637 & 9338.800 & 1.060 & -0.793 & 969.401 & 701.520 \\
FS & 4.619 & 0.632 & 0.399 & -1.042 & -0.933 & 5.150 & 3.540 \\
EI & 0.263 & 0.038 & 0.001 & -0.486 & -0.764 & 0.321 & 0.192 \\
ES & 0.060 & 0.04 & 0.002 & 0.693 & -1.348 & 0.132 & 0.020 \\
ES $_{2}$ & 0.530 & 0.053 & 0.003 & -0.501 & -0.711 & 0.616 & 0.441 \\
$\mathrm{ES}_{3}$ & 0.410 & 0.026 & 0.001 & -1.247 & 1.435 & 0.445 & 0.345 \\
\hline
\end{tabular}

Table A3. Detailed decomposition results of REC in urban Guangdong, (Ttce).

\begin{tabular}{ccccccc}
\hline Period & $\Delta \mathrm{E}_{\mathrm{ES}}$ & $\Delta \mathrm{E}_{\mathrm{EI}}$ & $\Delta \mathrm{E}_{\mathrm{CP}}$ & $\Delta \mathrm{E}_{\mathrm{FS}}$ & $\Delta \mathrm{E}_{\mathrm{H}}$ & $\Delta \mathrm{E}_{\mathrm{TOT}}$ \\
\hline $2000-2001$ & 0.00 & -18.15 & 44.40 & -8.60 & 30.27 & 47.93 \\
$2001-2002$ & 0.00 & -52.47 & 52.16 & -24.20 & 43.13 & 18.62 \\
$2002-2003$ & 0.05 & -12.73 & 68.19 & -16.47 & 38.12 & 77.15 \\
$2003-2004$ & 0.01 & -28.55 & 53.09 & -6.87 & 34.11 & 51.78 \\
$2004-2005$ & 0.03 & 111.89 & 52.92 & -2.66 & 26.04 & 188.22 \\
$2005-2006$ & 0.06 & -83.38 & 62.30 & 6.03 & 57.42 & 42.43 \\
$2006-2007$ & 0.06 & 0.04 & 67.22 & -6.45 & 32.87 & 93.75 \\
$2007-2008$ & 0.02 & -56.76 & 62.35 & 0.00 & 30.97 & 36.58 \\
$2008-2009$ & 0.01 & -87.64 & 133.61 & -7.23 & 35.67 & 74.42 \\
$2009-2010$ & 0.02 & -141.11 & 89.34 & -15.30 & 105.44 & 38.39 \\
$2010-2011$ & 0.21 & 112.33 & 90.86 & -4.24 & 19.33 & 218.48 \\
$2011-2012$ & 0.01 & -145.08 & 131.87 & -4.64 & 37.08 & 19.24 \\
$2012-2013$ & -0.01 & -154.13 & 98.15 & -306.67 & 321.44 & -41.22 \\
$2013-2014$ & 0.02 & 2.15 & 93.44 & 57.08 & -40.47 & 112.22 \\
$2014-2015$ & 0.12 & 56.19 & 100.00 & 48.57 & -12.15 & 192.72 \\
$2015-2016$ & 0.05 & 54.68 & 108.46 & 39.76 & -1.10 & 201.84 \\
$2016-2017$ & 0.00 & -102.27 & 112.57 & 27.90 & 21.17 & 59.38 \\
\hline
\end{tabular}

Table A4. Detailed decomposition results of REC in rural Guangdong, (Ttce).

\begin{tabular}{ccccccc}
\hline Period & $\Delta \mathrm{E}_{\mathrm{ES}}$ & $\Delta \mathrm{E}_{\mathrm{EI}}$ & $\Delta \mathrm{E}_{\mathrm{CP}}$ & $\Delta \mathrm{E}_{\mathrm{FS}}$ & $\Delta \mathrm{E}_{\mathrm{H}}$ & $\Delta \mathrm{E}_{\mathrm{TOT}}$ \\
\hline $2000-2001$ & 0.00 & 23.31 & 9.82 & -2.79 & -3.84 & 26.51 \\
$2001-2002$ & 0.00 & -4.89 & 15.05 & -1.19 & -1.87 & 7.10 \\
$2002-2003$ & 0.01 & 20.26 & 10.68 & -2.53 & -0.96 & 27.48 \\
$2003-2004$ & 0.01 & 7.89 & 13.42 & -2.04 & -1.88 & 17.39 \\
$2004-2005$ & 0.20 & 61.85 & 16.94 & -0.77 & -6.25 & 71.96 \\
$2005-2006$ & 0.04 & 2.44 & 26.60 & -1.72 & -12.94 & 14.42 \\
$2006-2007$ & 0.01 & 6.73 & 29.12 & 1.84 & 6.87 & 44.58 \\
$2007-2008$ & 0.01 & 31.13 & 37.89 & 0.00 & 9.19 & 78.22 \\
$2008-2009$ & 0.00 & -21.66 & 59.51 & -1.17 & 14.53 & 51.21 \\
$2009-2010$ & 0.01 & 10.06 & 61.91 & -5.08 & -25.54 & 41.35 \\
$2010-2011$ & 0.24 & 106.75 & 83.38 & -16.67 & 13.93 & 187.64 \\
$2011-2012$ & 0.00 & -35.25 & 75.83 & -3.53 & -12.49 & 24.56 \\
$2012-2013$ & -0.04 & -120.52 & 62.52 & -217.83 & 212.51 & -63.37 \\
$2013-2014$ & 0.01 & 1.46 & 66.54 & -39.16 & 39.18 & 68.02 \\
$2014-2015$ & 0.06 & 86.13 & 69.74 & 15.80 & -26.00 & 145.74 \\
$2015-2016$ & 0.01 & 57.76 & 67.61 & 26.56 & -28.77 & 123.18 \\
$2016-2017$ & 0.00 & -63.93 & 86.05 & -12.49 & 5.62 & 15.25 \\
\hline
\end{tabular}




\section{References}

1. Hang, Y.; Wang, Q.; Zhou, D.; Zhang, L. Factors influencing the progress in decoupling economic growth from carbon dioxide emissions in China's manufacturing industry. Resour. Conserv. Recycl. 2019, 146, 77-88. [CrossRef]

2. Zhao, X.; Zhang, X.; Li, N.; Shao, S.; Geng, Y. Decoupling economic growth from carbon dioxide emissions in China: A sectoral factor decomposition analysis. J. Clean. Prod. 2017, 142, 3500-3516. [CrossRef]

3. Wang, Q.; Zhao, M.; Li, R.; Su, M. Decomposition and decoupling analysis of carbon emissions from economic growth: A comparative study of China and the United States. J. Clean. Prod. 2018, 197, 178-184. [CrossRef]

4. Shi, Y.; Han, B.; Han, L.; Wei, Z. Uncovering the national and regional household carbon emissions in China using temporal and spatial decomposition analysis models. J. Clean. Prod. 2019, 232, 966-979. [CrossRef]

5. Hu, W.; Ho, M.S.; Cao, J. Energy consumption of urban households in China. China Econ. Rev. 2019, 58, 101343. [CrossRef]

6. Nie, H.; Kemp, R. Index decomposition analysis of residential energy consumption in China: 2002-2010. Appl. Energy 2014, 121, 10-19. [CrossRef]

7. Zhang, M.; Song, Y.; Li, P.; Li, H. Study on affecting factors of residential energy consumption in urban and rural Jiangsu. Renew. Sust. Energ. Rev. 2016, 53, 330-337. [CrossRef]

8. Fan, J.-L.; Zhang, Y.-J.; Wang, B. The impact of urbanization on residential energy consumption in China: An aggregated and disaggregated analysis. Renew. Sust. Energ. Rev. 2017, 75, 220-233. [CrossRef]

9. Qu, J.; Maraseni, T.; Liu, L.; Zhang, Z.; Yusaf, T. A comparison of household carbon emission patterns of urban and rural China over the 17 year period (1995-2011). Energies 2015, 8, 10537-10557. [CrossRef]

10. Chen, J.; Wu, Y.; Song, M.; Dong, Y. The residential coal consumption: Disparity in urban-rural China. Resour. Conserv. Recycl. 2018, 130, 60-69. [CrossRef]

11. Huang, R.; Zhang, S.; Liu, C. Comparing urban and rural household $\mathrm{CO}_{2}$ emissions-Case from China's four megacities: Beijing, Tianjin, Shanghai, and Chongqing. Energies 2018, 11, 1257. [CrossRef]

12. Chen, C.; Liu, G.; Meng, F.; Hao, Y.; Zhang, Y.; Casazza, M. Energy consumption and carbon footprint accounting of urban and rural residents in Beijing through Consumer Lifestyle Approach. Ecol. Indic. 2019, 98, 575-586. [CrossRef]

13. Das, A.; Paul, S.K. $\mathrm{CO}_{2}$ emissions from household consumption in India between 1993-94 and 2006-07: A decomposition analysis. Energy Econ. 2014, 41, 90-105. [CrossRef]

14. Pachauri, S.; Spreng, D. Direct and indirect energy requirements of households in India. Energy Policy 2002, 30, 511-523. [CrossRef]

15. Bin, S.; Dowlatabadi, H. Consumer lifestyle approach to US energy use and the related $\mathrm{CO}_{2}$ emissions. Energy Policy 2005, 33, 197-208. [CrossRef]

16. Park, H.-C.; Heo, E. The direct and indirect household energy requirements in the Republic of Korea from 1980 to 2000-An input-output analysis. Energy Policy 2007, 35, 2839-2851. [CrossRef]

17. Zhang, M.; Bai, C. Exploring the influencing factors and decoupling state of residential energy consumption in Shandong. J. Clean. Prod. 2018, 194, 253-262. [CrossRef]

18. Li, Y.; Yang, T. Comparison of urban and rural household direct energy consumption and $\mathrm{CO}_{2}$ emissions. Resour. Sci. 2013, 35, 115-124. (In Chinese)

19. Wei, Y.-M.; Liu, L.-C.; Fan, Y.; Wu, G. The impact of lifestyle on energy use and $\mathrm{CO}_{2}$ emission: An empirical analysis of China's residents. Energy Policy 2007, 35, 247-257. [CrossRef]

20. Feng, Z.-H.; Zou, L.-L.; Wei, Y.-M. The impact of household consumption on energy use and $\mathrm{CO}_{2}$ emissions in China. Energy 2011, 36, 656-670. [CrossRef]

21. Zhang, Y.-J.; Bian, X.-J.; Tan, W.; Song, J. The indirect energy consumption and $\mathrm{CO}_{2}$ emission caused by household consumption in China: An analysis based on the input-output method. J. Clean. Prod. 2017, 163, 69-83. [CrossRef]

22. Liu, Z.; Zhao, T. Contribution of price/expenditure factors of residential energy consumption in China from 1993 to 2011: A decomposition analysis. Energy Conv. Manag. 2015, 98, 401-410. [CrossRef]

23. Xiao, B.; Niu, D.; Guo, X. The driving forces of changes in $\mathrm{CO}_{2}$ emissions in China: A structural decomposition analysis. Energies 2016, 9, 259. [CrossRef]

24. Su, B.; Ang, B.W. Structural decomposition analysis applied to energy and emissions: Some methodological developments. Energy Econ. 2012, 34, 177-188. [CrossRef] 
25. Jia, J.; Gong, Z.; Gu, Z.; Chen, C.; Xie, D. Multi-perspective comparisons and mitigation implications of $\mathrm{SO}_{2}$ and NOx discharges from the industrial sector of China: A decomposition analysis. Env. Sci. Pollut. Res. Int. 2018, 25, 9600-9614. [CrossRef] [PubMed]

26. Jia, J.; Gong, Z.; Xie, D.; Chen, J.; Chen, C. Analysis of drivers and policy implications of carbon dioxide emissions of industrial energy consumption in an underdeveloped city: The case of Nanchang, China. J. Clean. Prod. 2018, 183, 843-857. [CrossRef]

27. Ang, B.W.; Liu, F.L.; Chew, E.P. Perfect decomposition techniques in energy and environmental analysis. Energy Policy 2003, 31, 1561-1566. [CrossRef]

28. Ang, B.W. Decomposition analysis for policymaking in energy: Which is the preferred method? Energy Policy 2004, 32, 1131-1139. [CrossRef]

29. Zhao, X.; Li, N.; Ma, C. Residential energy consumption in urban China: A decomposition analysis. Energy Policy 2012, 41, 644-653. [CrossRef]

30. National Bureau of Statistic of China. China Energy Statistical Yearbook; China Statistics Press: Beijing, China, 2001-2018. (In Chinese)

31. Tian, X.; Geng, Y.; Dong, H.; Dong, L.; Fujita, T.; Wang, Y.; Zhao, H.; Wu, R.; Liu, Z.; Sun, L. Regional household carbon footprint in China: A case of Liaoning province. J. Clean. Prod. 2016, 114, 401-411. [CrossRef]

32. Statistics Bureau of Guangdong. Guangdong Statistical Yearbook; China Statistics Press: Beijing, China, 2001-2018. (In Chinese)

33. Zhao, M.-M.; Li, R. Decoupling and decomposition analysis of carbon emissions from economic output in Chinese Guangdong Province: A sector perspective. Energy Environ. 2018, 29, 543-555. [CrossRef]

34. Zhen, W.; Zhong, Z.; Wang, Y.; Miao, L.; Qin, Q.; Wei, Y.-M. Evolution of urban household indirect carbon emission responsibility from an inter-sectoral perspective: A case study of Guangdong, China. Energy Econ. 2019, 83, 197-207. [CrossRef]

35. Jiang, J.-J.; Ye, B.; Zhou, N.; Zhang, X.-L. Decoupling analysis and environmental Kuznets curve modelling of provincial-level $\mathrm{CO}_{2}$ emissions and economic growth in China: A case study. J. Clean. Prod. 2019, 212, 1242-1255. [CrossRef]

36. Zhang, Z. Decoupling China's carbon emissions increase from economic growth: An economic analysis and policy implications. World Dev. 2000, 28, 739-752. [CrossRef]

37. OECD. Indicators to Measure Decoupling of Environmental Pressure from Economic Growth; OECD: Paris, France, 2002.

38. Juknys, R. Transition Period in Lithuania-Do we move to sustainability? Env. Res. Eng. Manag. 2003, 4, 4-9.

39. Tapio, P. Towards a theory of decoupling: Degrees of decoupling in the EU and the case of road traffic in Finland between 1970 and 2001. Transp. Policy 2005, 12, 137-151. [CrossRef]

40. Wang, Q.; Jiang, R.; Zhan, L. Is decoupling economic growth from fuel consumption possible in developing countries?-A comparison of China and India. J. Clean. Prod. 2019, 229, 806-817. [CrossRef]

41. Ma, M.; Cai, W.; Cai, W.; Dong, L. Whether carbon intensity in the commercial building sector decouples from economic development in the service industry? Empirical evidence from the top five urban agglomerations in China. J. Clean. Prod. 2019, 222, 193-205. [CrossRef]

42. Luo, Y.; Long, X.; Wu, C.; Zhang, J. Decoupling $\mathrm{CO}_{2}$ emissions from economic growth in agricultural sector across 30 Chinese provinces from 1997 to 2014. J. Clean. Prod. 2017, 159, 220-228. [CrossRef]

43. Wu, Y.; Chau, K.W.; Lu, W.; Shen, L.; Shuai, C.; Chen, J. Decoupling relationship between economic output and carbon emission in the Chinese construction industry. Env. Impact Assess. Rev. 2018, 71, 60-69. [CrossRef]

44. Diakoulaki, D.; Mandaraka, M. Decomposition analysis for assessing the progress in decoupling industrial growth from $\mathrm{CO}_{2}$ emissions in the EU manufacturing sector. Energy Econ. 2007, 29, 636-664. [CrossRef]

45. Dong, B.; Zhang, M.; Mu, H.; Su, X. Study on decoupling analysis between energy consumption and economic growth in Liaoning Province. Energy Policy 2016, 97, 414-420. [CrossRef]

46. Zhao, X.; Zhang, X.; Shao, S. Decoupling $\mathrm{CO}_{2}$ emissions and industrial growth in China over 1993-2013: The role of investment. Energy Econ. 2016, 60, 275-292. [CrossRef]

47. Román-Collado, R.; Cansino, J.M.; Botia, C. How far is Colombia from decoupling? Two-level decomposition analysis of energy consumption changes. Energy 2018, 148, 687-700. [CrossRef]

48. Wang, Y.; Xie, T.; Yang, S. Carbon emission and its decoupling research of transportation in Jiangsu Province. J. Clean. Prod. 2017, 142, 907-914. [CrossRef] 
49. Kaya, Y. Impact of Carbon Dioxide Emission Control on GNP Growth: Interpretation of Proposed Scenarios; IPCC Energy and Industry Subgroup, Response Strategies Working Group: Paris, France, 1990.

50. Chung, W.; Kam, M.S.; Ip, C.Y. A study of residential energy use in Hong Kong by decomposition analysis, 1990-2007. Appl. Energy 2011, 88, 5180-5187. [CrossRef]

51. Zang, X.; Zhao, T.; Wang, J.; Guo, F. The effects of urbanization and household-related factors on residential direct $\mathrm{CO}_{2}$ emissions in Shanxi, China from 1995 to 2014: A decomposition analysis. Atmos. Pollut. Res. 2017, 8, 297-309. [CrossRef]

52. Chen, J.; Peng, X.; Zhu, Q. Impacts of household pattern on carbon emission. Chin. J. Popul. Sci. 2009; 5, 68-78. (In Chinese)

53. Ang, B.W.; Liu, N. Handling zero values in the logarithmic mean Divisia index decomposition approach. Energy Policy 2007, 35, 238-246. [CrossRef]

54. Wang, Q.; Zhao, M.; Li, R. Decoupling sectoral economic output from carbon emissions on city level: A comparative study of Beijing and Shanghai, China. J. Clean. Prod. 2019, 209, 126-133. [CrossRef]

55. Wang, Q.; Wang, S. Decoupling economic growth from carbon emissions growth in the United States: The role of research and development. J. Clean. Prod. 2019, 234, 702-713. [CrossRef]

56. Zhang, X.; Luo, L.; Skitmore, M. Household carbon emission research: An analytical review of measurement, influencing factors and mitigation prospects. J. Clean. Prod. 2015, 103, 873-883. [CrossRef]

57. Sathaye, J.; Meyers, S. Energy use in cities of the developing countries. Ann. Rev. Energy 1985, 10, 109-133. [CrossRef]

58. Yang, Y.; Jia, J.; Chen, C. Residential energy-related $\mathrm{CO}_{2}$ emissions in China's less developed regions: A case study of Jiangxi. Sustainability 2020, 12, 2000. [CrossRef]

59. Xie, P.; Gao, S.; Sun, F. An analysis of the decoupling relationship between $\mathrm{CO}_{2}$ emission in power industry and GDP in China based on LMDI method. J. Clean. Prod. 2019, 211, 598-606. [CrossRef]

60. Chen, $X$. The one-child population policy, modernization, and the extended Chinese family. J. Marriage Fam. 1985, 47, 193-202. [CrossRef]

(C) 2020 by the authors. Licensee MDPI, Basel, Switzerland. This article is an open access article distributed under the terms and conditions of the Creative Commons Attribution (CC BY) license (http://creativecommons.org/licenses/by/4.0/). 